Running head: Pro-white bias in rural Uganda

1

2

3

4

5

6

7

8

9

10

11

12

13

14

15

16

17

18

19

\section{The Role of Status in the Emergence of Pro-White Bias in Rural Uganda}

\author{
Authors: \\ Julia Marshall ${ }^{1,2 * \wedge}$, \\ Anton Gollwitzer ${ }^{1 *}$, \\ Kellen Mermin-Bunnell ${ }^{1}$, \& \\ Tara Mandalaywala ${ }^{3}$
}

\section{Affiliations:}

${ }^{1}$ Yale University

${ }^{2}$ Boston College

${ }^{3}$ University of Massachusetts Amherst 6

*Shared first-authorship

${ }^{\wedge}$ Correspondence to Julia Marshall, marshaau@bc.edu 


\section{Research Highlights}

- The present study examines the early emergence of pro-White bias, race-based status judgments, and the relationship between the two in a sample of rural Ugandan children.

- Ugandan children between the ages of five and twelve exhibit pro-White bias.

- Additionally, Ugandan children consider White individuals higher in status than Black individuals, a belief that strengthens with age.

- Importantly, the degree to which children consider White individuals higher in status than Black individuals positively predicts their pro-White bias. 


\section{Abstract}

31 Research investigating the early emergence of racial prejudice has been largely limited to contexts 32 in which racial prejudice is most likely to emerge - multiracial societies that have pronounced 33 racial inequality (e.g., United States, South Africa). The present study assessed whether pro-White 34 racial bias is also early emerging in a homogenous Black community that has little exposure to 35 modern media and where children presumably experience less overt discrimination than in past 36 samples (e.g., South Africa). Black African children $(N=214)$ between 5- and 12-years-old living 37 in rural Uganda exhibited substantial pro-White racial bias, preferring White over Black children $3878 \%$ of the time. Ugandan children also judged White children as higher status than Black children, 39 and these status judgments predicted their degree of pro-White bias. Our results indicate that pro40 White racial biases can emerge even in a homogenous Black community and that, in some 41 contexts, minimal status cues are sufficient for the early development of racial prejudice.

$42 \quad$ Keywords: social status, race, prejudice, development 


\section{The Role of Status in the Early Emergence of Pro-White Bias in Rural Uganda}

Racial prejudice — whether individually harbored or structurally ingrained — has numerous deleterious consequences in society, including a variety of social and health issues (e.g., Brondolo et al., 2012; Lee et al., 2015). Given these pernicious outcomes, ample research in psychology and sociology has attempted to identify ways to attenuate prejudice. In these research efforts, developmental psychology has played a key role by documenting the ages at which prejudice first emerges and what factors maintain these problematic attitudes through childhood. As Bigler and Liben (2007) argued, "Because stereotyping and prejudice emerge in early childhood, developmental research on causal mechanisms is critical for understanding and controlling stereotyping and prejudice" (p. 162).

Developmental research on prejudice has predominantly focused on prejudice against outgroups stereotyped as lower status, the age at which prejudicial attitudes begin to emerge, and, to a lesser degree, the factors that incite prejudice in children (e.g., Aboud, 1988; Aboud \& Steele, 2017; Bigler \& Liben, 2006). Meta-analytic findings indicate that explicit racial prejudice against outgroups stereotyped as lower status emerges between the ages of two and four and increases substantially between the ages of five and seven (Raabe \& Beelmann, 2011). By age eight, these explicit biases — unlike implicit racial biases (e.g., Baron \& Banaji, 2006) — generally diminish as children begin to embrace egalitarian principles, forming what has been called an "inverted Ushaped curve." Notably, this early emergence of prejudice is not solely driven by ingroup favoritism (i.e., favoring one's own group). Even children who are members of racially minoritized groups (e.g., Black children in the United States) tend to either prefer White over Black individuals or do not exhibit a preference for their own racial in-group to the same extent that White children do (they exhibit "asymmetric" preference; Aboud \& Skerry, 1984; though, pro-Black attitudes have also been observed in some cases — see Branch \& Newcombe, 1986; Hraba \& Grant, 1970). 
If the early emergence of racial prejudice is not solely driven by ingroup favoritism, then why do biased racial preferences emerge early in life? Researchers have theorized that social status plays a pivotal role in the development of racial prejudice (Bigler \& Liben, 2006; Shutts, 2015).

That is, children may recognize that certain racial groups are perceived and treated as higher status than others in society. Indeed, in the United States there are pervasive differences in education, income, and wealth between White and Black individuals due to racial oppression and marginalization in the United States (e.g., Feagin, 2013; Pew Research Center, 2016). This realization may in turn play a role in shaping the early emergence of racial prejudice.

Some empirical research, albeit indirectly, provides support for status differences underlying the early emergence of racial prejudice. For example, meta-analytic results indicate that children exhibit greater prejudice towards low compared to high status outgroups in early and middle childhood (Raabe \& Beelmann, 2011). Additionally, White children associate White targets with greater resources than Black targets (Elenbaas \& Killen, 2016; Shutts et al., 2016; see Qian et al., 2019 for similar effect in China). Indicating that these associations play a role in bias, children as young as four in general also prefer individuals who are described as wealthier (Horwitz et al., 2014; Sigelman, 2012). Though these studies suggest that status may play a role in racial prejudice, they do not directly examine this question.

Of the studies that have directly examined the link between status and racial prejudice in the United States, however, most have yielded mixed results (e.g., Mandalaywala et al., 2020; Newheiser \& Olson, 2012). For example, Mandalaywala and colleagues (2020) found that children's status judgments inconsistently predicted their racial preferences (e.g., wanting to play with White children, wanting to invite White children to a birthday party). That is, children's "ladder" judgments (i.e., where they placed an individual on a status ladder) weakly predicted their racial preference, whereas their "wealth association" judgments (i.e., whether they associated 
White individuals with nicer houses over less nice ones) did not predict their racial preference.

These mixed findings may in part arise because the racial dynamics of the United States introduce numerous confounds that may obscure a potential link between status and racial prejudice. For instance, White individuals in the United States are not only perceived as higher status but are also more populous and more prominently displayed in the media. Additionally, pervasive racismboth historically and presently_may influence the early emergence of racial prejudice even without any direct status cues (or suppress any potential impact of status). Indeed, children in the United States may exhibit racial prejudice as a result of witnessing prejudicial verbal and nonverbal cues (e.g., gaze aversion; Weisbuch et al., 2009) rather than because they hold explicit knowledge of status differences.

To account for these third-variables, researchers have begun to focus on communities outside of the United States (e.g., Brunei, Japan, South Africa; Steele et al., 2018; Dunham et al., 2006; Shutts et al., 2011, respectively). By identifying cultures that differ on the above dimensions (e.g., group size, familiarity, structural racism), researchers can better test the hypothesis that status is a key factor underlying the early emergence of racial prejudice. Particularly relevant to the current research, several studies have examined children's prejudice_—both implicit and explicit— in Africa (e.g., Duckitt et al., 1999; Fincham, 1978; Gregor \& McPherson, 1966; Press et al., 1979; Qian et al., 2021). Because Black individuals represent a clear majority in African countries, research conducted in these locations may better isolate the role that status plays in shaping racial prejudice.

Despite Black individuals being more populous in Africa, research has found that African Black children—like children in the United States (Aboud \& Skerry, 1984)—-tend to exhibit proWhite racial bias (Dunham et al., 2014; Shutts et al., 2011; Olson et al., 2012) or prefer Black and White individuals equally (reflecting a lack of in-group bias; Newheiser et al., 2014; Qian et al., 
118 2021). Because these studies were conducted in places where Black individuals are the majority

119 and are familiar — but are lower in social status (the majority of studies were conducted in South

120 Africa) - researchers have argued that the observed pro-White bias is driven by race-based status

121 cues and not relative group size or familiarity. For instance, Shutts and colleagues (2011) argue

122 that the early emergence of pro-White bias is "not likely explained by the greater size and

123 familiarity of that racial group" and that such biased racial preferences "appear to reflect the

124 relative status of different racial groups" (p. 1288).

125 Yet, as in the United States, the few studies that have directly examined the relationship

126 between status and racial prejudice in Africa have produced mixed findings (e.g., Dunham et al.,

127 2014; Olson et al., 2012; Qian et al., 2021; also see, Qian et al., 2019, for research in China). For

128 instance, Olson and colleagues (2010) found that 3- to 10-years-old South African children

129 associate higher value goods (e.g., a nice house, fancy car) with White individuals, and further,

130 prefer White individuals over Black individuals; yet, importantly, they did not find a robust

131 relationship between these two judgments (the correlation was marginally significant).

132 Furthermore, similar non-significant links between status and racial bias were documented in Qian

133 et al's (2021) research with children in Cameroon and in Dunham et al's (2014) research with

134 children in South Africa.

135 The previous research examining racial prejudice in Africa may be limited in certain ways,

136 however. As previously argued (Newheiser et al., 2014; Olson et al., 2010; Shutts et al., 2011),

137 South Africa - the country in which most of these studies were conducted (though see Qian et al.

138 2021) - is marked by extreme status differentials and historically sanctioned racial oppression

139 (Apartheid). As such, South Africa is a place where racial prejudice is especially likely to emerge 140 and where prejudice may arise via mechanisms other than status cues (e.g., verbal and nonverbal

141 prejudicial cues). Additionally, children in past studies in Africa presumably had access to media 
142 sources (e.g., television), in turn perhaps leading them to internalize or echo racial biases

143 (Weisbuch et al., 2009). As such, in these contexts, third-variables-factors apart from status

144 beliefs that could contribute to prejudice - may take precedence and attenuate or eliminate any 145 impact of status on prejudice.

146 The Current Work

147 The present work aims to contribute to past literature on the development of prejudice by 148 testing the early emergence of race-based status beliefs and racial prejudice in a novel cultural 149 context: A low socioeconomic status (SES) village in rural Uganda. Importantly, this 150 developmental sample extends past work in two key ways.

First, participants in our sample_-unlike in the United States and South Africa (but like in

152 Cameroon; Qian et al., 2021)—have had little exposure to White people. The percentage of White 153 people is nearly zero (at the time of data collection, no White people lived in the small village 154 where the study was conducted). Indeed, interviews with community members and census data 155 (National Census Data, 2014; World Bank Database: Uganda, 2021) revealed that children in our 156 sample rarely interacted with White people (once every 1 to 2 years) - largely in the context of 157 humanitarian aid work. Additionally, children in our sample have little exposure to online or 158 television media (National Census Data, 2014; World Bank Database: Uganda, 2021), which 159 minimizes the likelihood that children witness racial bias via nonverbal or verbal media cues 160 (Weisbuch et al., 2009). As such, our study can elucidate whether racial bias can emerge even in 161 a homogenously Black community that has very limited exposure to White people. Second, most studies have focused on examining race-based status judgments and racial 163 bias in places with pronounced systemic racial inequalities. That is, past studies have been 164 predominantly conducted in the United States and South Africa (e.g., Dunham et al., 2014; Olson 165 et al., 2012) — societies where extreme anti-Black state-sanctioned racial oppression has occurred 
166 (slavery, Apartheid) and overt racial discrimination remains common. Though Uganda was a

167 British colony and remains part of the British Commonwealth, Black people in Uganda—at least

168 comparatively - currently experience less overt and regular racial discrimination than Black

169 people in the United States and South Africa. ${ }^{1}$ Because of this, our study can provide insight into

170 whether racial prejudice emerges in contexts where children are comparatively less exposed to

171 anti-Black racial discrimination.

172

173

174

175

176

177

178

179

180

181

182

183

184

185

186

187

Although the noted features of our sample (e.g., limited exposure to White people, comparatively less racial discrimination) suggest that Ugandan children may not exhibit pro-White racial bias, several other factors indicate that such bias could emerge at a young age. For one, our sample_like some samples in South Africa (e.g., Dunham et al., 2014) but unlike the sample from Cameroon (e.g., Qian et al., 2021) —included children from a remote, low SES community (National Census Data, 2014). Notably, children low in SES may be more acutely aware of racebased status differences (Odgers \& Adler, 2017) and also may be more motivated to affiliate with high status individuals, which in turn may induce pro-White bias.

Second, Uganda was a British colony and remains part of the British Commonwealth. Colonization undoubtedly shapes a culture even after its end, and it is possible that children in Uganda — through subtle or overt cues — adopt stereotypical beliefs about Black and White racial groups even in the absence of direct exposure to White people, television media, or the internet (e.g., Fanon, 1967; Memmi, 1965; Williams, 2012). Indeed, colonization may manifest in the idealization of Whiteness and specifically lighter skin, which is commonplace in many parts of Africa. This form of "internalized oppression" is captured, for instance, by the popularity of cosmetic whitening products (e.g., skin-bleaching creams), the commonly held belief that Jesus

\footnotetext{
${ }^{1}$ Although, notably, Uganda has experienced state-sanctioned racial oppression against other groups (persecution of Asians and ethnic minorities in the 1970s; Baker, 2001).
} 
188

189

was White, and the importance placed on learning the English language - a language associated with Whiteness (e.g., Hunter, 2011; Maddox \& Gray, 2002; Okazawa-Rey et al., 1987; No White Saviors, 2019; Von Esch et al., 2020). In sum, our study can provide insight into whether past and present racial inequalities and prejudice are pervasive enough to shape race-based status differences and pro-White bias even in young children in a fairly remote and homogenously Black community in Uganda.

With this in mind, the present study tested whether 5 through 12-year-old Black Ugandan children $(N=214)$ in a rural village ascribe higher status to White (than Black) people, exhibit pro-White racial bias, and whether participants' status judgments predict pro-White racial bias. Importantly, unlike most previous work on racial bias in childhood, this community (a) is homogenous (all Black) and has little access to media, and (b) is comparatively less exposed to individual and structural racism than previous samples (e.g., United States, South Africa). In examining this sample, the present work helps shed light on the contexts in which pro-White racial bias develops, and further, the potential factors driving the early emergence of such bias.

\section{Method}

Participants and Sample Characteristics. We tested 214 children (109 females) between the ages of 5 and 12 years old $(M=8.74, S D=2.28)$ at a primary school during the summer of 2019. We aimed to test as many students as possible with at least 20 children per categorical age.

Ultimately, we tested 20 5-year-olds, 26 6-year-olds, 25 7-year-olds, 21 8-year-olds, 42 9-yearolds, 20 10-year-olds, 23 11-year-olds, and 36 12-year-olds. With the total sample $(N=214)$, we had sufficient power $(90 \%)$ to detect a significant correlation (between prejudice and status) if this correlation is $r=.22$ or greater in the population. We were only able to collect children's age in years, as many children did not know their exact birth date. Some of the participants in the study participated in several other tasks during the experimental session. These other tasks included, for 
212 example, making predictions about who is likely to help, rating patterned and unpatterned images,

213 and making inferences about novel groups depending on their group size. These measures are not

214 presented here as they do not pertain to the presented research question.

215 The study was conducted in the Mukono District in southeastern Uganda about 40

216 kilometers southeast of Kampala (Uganda's capital). The school at which we recruited participants

217 is approximately 5 kilometers outside of the nearest village; students reside both in neighboring

218 villages and on surrounding subsistence farmland. The dominant religion is Christianity (37\%

219 Catholic, 33\% Anglican), followed by Islam (21\%) and tribal religions (9\%). The official language

220 is English, which is taught in schools, but the common language is Luganda, the language of the

221 Buganda, the dominant tribe in the region. Most of the population lives remotely and has little (if

222 any) exposure to television and media. Some families may have radios and listen to popular

223 Ugandan music as well as some international artists. The school where we collected data has

224 students ranging in age from 4 to 16, with children of mixed ages in each class (approximately 50

225 students per classroom) for a total of about 400 students.

Procedure and Materials. Participants responded to two measures (presented on an iPad):

227 a status task and a racial bias measure. The order of these measures was counterbalanced across

228 participants. The study was conducted by local research assistants who were all Black African

229 individuals and spoke the native language, Luganda. Although the third author (who is White) was

230 present during the time of testing, she did not conduct the study herself. Importantly, she was never

231 directly involved in testing children; the majority of testing sessions occurred outdoors on the

232 school premises in isolated locations that were removed from other people. Additionally, the third

233 author ensured that she was perceived as a member of the research team and not the "leader" of

234 the group - all the researchers were introduced as equal members of the research team and were

235 around the same age. Finally, all individuals at the school received a gift at the end of data 
236 collection in the form of a pencil or pen. This was chosen as a gift because it helps students conduct 237 their schoolwork but is not too ostentatious. All the team members distributed the gifts to students 238 after participating in the study or at the end of the school day. The study was translated into 239 Luganda by a bilingual research assistant, back-translated into English by a different translator, 240 then edited and re-translated into Luganda. For all participants, the study was presented in 241 Luganda. See link for Open Science Framework (OSF) for verbatim scripts. Race-Based Status Measure. The status measure entailed a "ladder" task based directly 243 off of a study examining status and racial bias in children in the United States (Mandalaywala et 244 al., 2020); a version of this task has also been validated cross-culturally (Amir et al., 2019). 245 Experimenters first instructed children how the ladder task works in Luganda (translated here; 246 Figure 1): "In this activity, I'm going to ask you about where people go on this ladder. Kids on the 247 top of the ladder have lots of toys and new clothes, and they always get to pick the games that 248 everyone else plays. Kids at the bottom of the ladder don't have any toys or new clothes, and they 249 never get to pick the games that anyone plays. Kids don't go just at the top or the bottom. They 250 can go at any of these places in the middle too." 
(1) Ladder Introduction



In this activity, I'm going to ask you about where people go on this ladder. Kids on the top of the ladder have lots of toys and new clothes, and they always get to pick the games that everyone else plays. Kids at the bottom of the ladder don't have any toys or new clothes, and they never get to pick the games that anyone plays. Kids don't go just at the top or the bottom. They can go at any of these places in the middle too.
(2) Example Trial



Here are two kids.

We're going to put them on the ladder!

Remember!

Kids of the top of the ladder have lots of toys and new clothes, and they always get to pick the games that everyone else plays.

Kids at the bottom of the ladder don't have any toys or new clothes, and they never get to pick the games that anyone plays. (2a) Ladder Assignment; Black Target

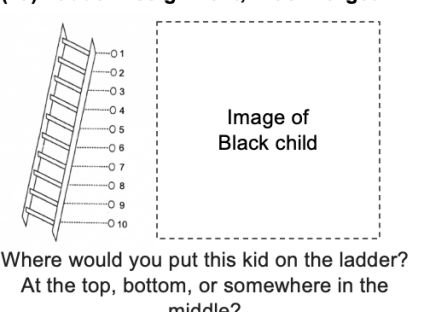

(2b) Ladder Assignment; White Target

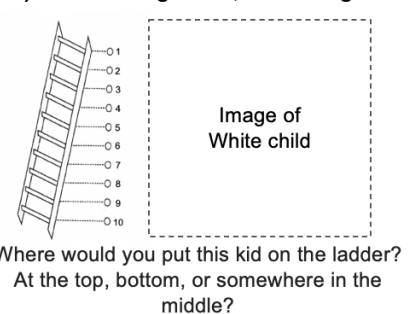

Figure 1 Main methodological approach. (1) Ladder introduction: Experimenters introduced participants to the ladder task. (2) The experimenter presented eight different target pairs. Each trial depicted two children - one Black and one White (side of the screen was counterbalanced). The exact images used are not depicted here for copyright reasons; see OSF link for exact materials. For each trial, experimenters asked participants to rank each child on the ladder. We counter-balanced whether participants ranked the White or Black target first. Half of the trials featured boys; the other half featured girls. Half of the trials featured faces from the CAFE database; the other half featured faces collected on Google Images (the latter is depicted here).

randomized within each participant) featuring pairs of children varying in race (one White, one Black). Specifically, for each trial, an experimenter said, "Here are two kids. We're going to put them on the ladder! Remember, kids at the top of the ladder have lots of toys and new clothes, and they always get to pick the games that everyone else plays. Kids at the bottom of the ladder don't have any toys or new clothes, and they never get to pick the games that anyone plays." Following the presentation of the two targets, the experimenter had participants individually place the White target and Black target on the status ladder for each trial in a counterbalanced fashion by asking, 
"Where would you put this kid on the ladder? At the top, bottom, or somewhere in between?" (Figure 1). We presented the two targets simultaneously because making decisions about status is inherently relational, and we wanted to increase the chances that children noticed race when making their judgments. Importantly, because the measure assessed children's tendency to use racial category membership when judging individual people, participants' responses can be thought of as status "stereotypes" that children hold towards specific racial groups (see Hamilton, 1981).

Notably, the faces included in our measure were sourced from two different databasesone set featured White and Black children from a standardized face image database [Child Affective Facial Expression (CAFE) set; henceforth, CAFE faces; LoBue \& Thrasher, 2014, 2015] and one set featured White and Black children from Google Images. The CAFE faces featured African American children with generally lighter skin tone with neutral expressions in plain clothing. The Google Image faces featured African children with generally dark skin tone with positive emotional expression in everyday clothing. We exploratorily examined whether our effects differed depending on stimuli set (CAFE, Google Image). Beyond stimuli set, half of the trials included male targets varying in race; the other half included female targets varying in race. As additional measures, we also included four gender trials (all Black faces) as well as had participants place themselves on the status ladder; see Supplemental Online Material (SOM) for results of these additional measures.

Racial Bias Measure. For the racial bias measure, experimenters presented participants with eight pairs of children and for each pair asked, "Who do you want to play with? This kid or this kid?" We based this measure off of previous work utilizing biased racial preferences as an index of racial bias or prejudice (e.g., Baron \& Banaji, 2006; Dunham et al., 2006; Mandalaywala et al., 2020; Qian et al., 2021). The pairs of children were the same pairs of children used in the 
status ladder task. For an example, see Panel 2 of Figure 1. The same counterbalancing and randomization procedures were applied.

Stimuli Validation. To verify that the faces presented in each pair did not systematically vary on dimensions other than race, we conducted an online validation study with adults in the United States $\left(n=48 ; 16\right.$ Female; $M_{\text {age }}=42.65, S D_{\text {age }}=12.38 ; 41=$ White, $4=$ Black, $3=$ Asian, 3 = Latinx/Hispanic) on Amazon Mechanical Turk (MTurk). In this study, MTurk participants rated the 16 faces individually on four dimensions - attractiveness, symmetry, happiness, and age. We did not find differences in participants' ratings of White and Black faces' attractiveness or symmetry, $p>.169$, however, we did find differences in participants' ratings of happiness and age. The Black faces were rated as happier, $p=.002$ - this effect should work against any pro-White bias since participants should want to play with happier individuals. Additionally, the Black faces were rated as slightly older (by $\sim 0.31$ years), $p=.033$. This difference is unlikely to impact our findings, though, because children, in general, are equally willing to play with same-aged peers and older ones (Edwards \& Lewis, 1979; French, 1979). Finally, though these data provide some support for the validity of our stimuli, this support is clearly limited because participants in our validation study were predominantly White American adults and not Ugandan children.

\section{Results}

We first examined participants' racial bias. A one sample t-test revealed that the Ugandan children overwhelmingly exhibited a pro-White bias; despite themselves being Black, they chose to play with White children over Black children $78 \%$ of the time, $M=.78, S D=.22, \omega_{t}=.77$, $t(213)=18.08, p<.001, d=1.24(0=$ Black target, $1=$ White target; Figure 2A $)$. Demonstrating robustness across participants, a generalized linear model (GLM) modeled onto a Poisson distribution (to account for the skewed distribution of participants' pro-White bias) indicated that the observed racial bias did not differ by participants' age (Figure 2B) or gender, ps $>.201$. 
318 Notably, the observed racial bias was also found when the one sample t-test was restricted to the 319 youngest participants - 5-year-olds chose the White target in $79 \%$ of trials, $t(19)=6.36, p<.001$, $320 \quad d=1.41$.

As noted in the Methods, the target faces featured both CAFE (i.e., White targets and Black

322 targets with lighter skin tones from a facial image database) and Google Image faces (i.e., White 323 targets and Black targets with darker skin tones from Google Images), as well as both male and 324 female faces. To examine whether the observed effects varied as a function of stimuli set and 325 gender, we conducted a generalized estimating equation (GEE) modeled onto a Poisson 326 distribution with Stimuli Set (CAFE and Google Images) and Target Gender (male and female) as 327 within-participant factors; participants' race bias functioned as the outcome variable. We found 328 that participants chose to play with White over Black Google Image targets $(79.65 \%$ of trials, $t=$ $32915.98, p<.001)$ to a greater extent than they chose to play with White over Black CAFE targets $330(75.95 \%$ of trials, $t=14.95, p<.001), B=.17, \chi^{2}=4.15, p=.042$-although, this effect was quite 331 small. It is possible these differences emerged because of colorism (i.e., prejudice against those 332 with darker skin tone; Maddox \& Gray, 2002; Stepanova et al., 2021), given the Google Image 333 faces featured Black children with darker skin tones and the CAFE featured Black children with 334 lighter skin tones. Regarding target gender, participants chose to play with White over Black 335 targets to a greater extent for male targets $(82.35 \%$ of trials, $t=18.84, p<.001)$ than for female 336 targets $(73.25 \%$ of trials, $t=11.88, p<.001), B=.42, \chi^{2}=22.14, p<.001$. 
(A)

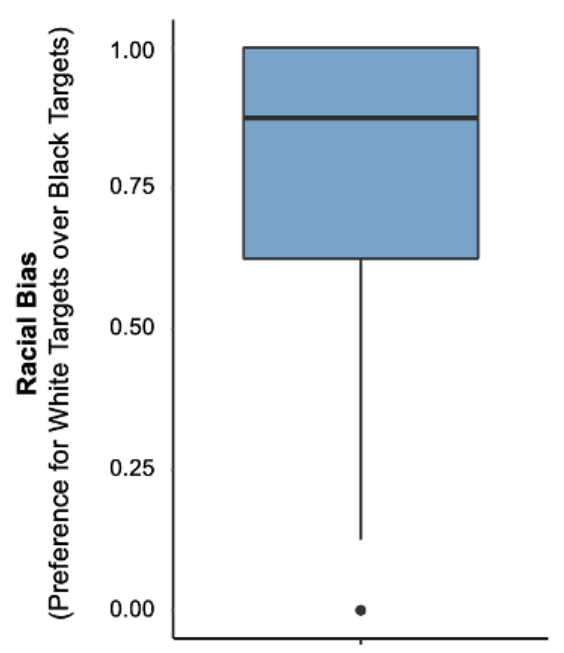

(C)

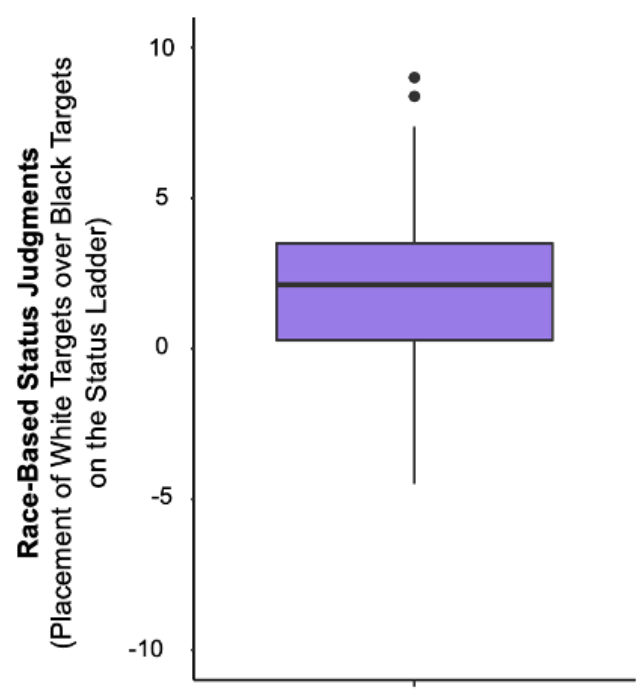

(B)

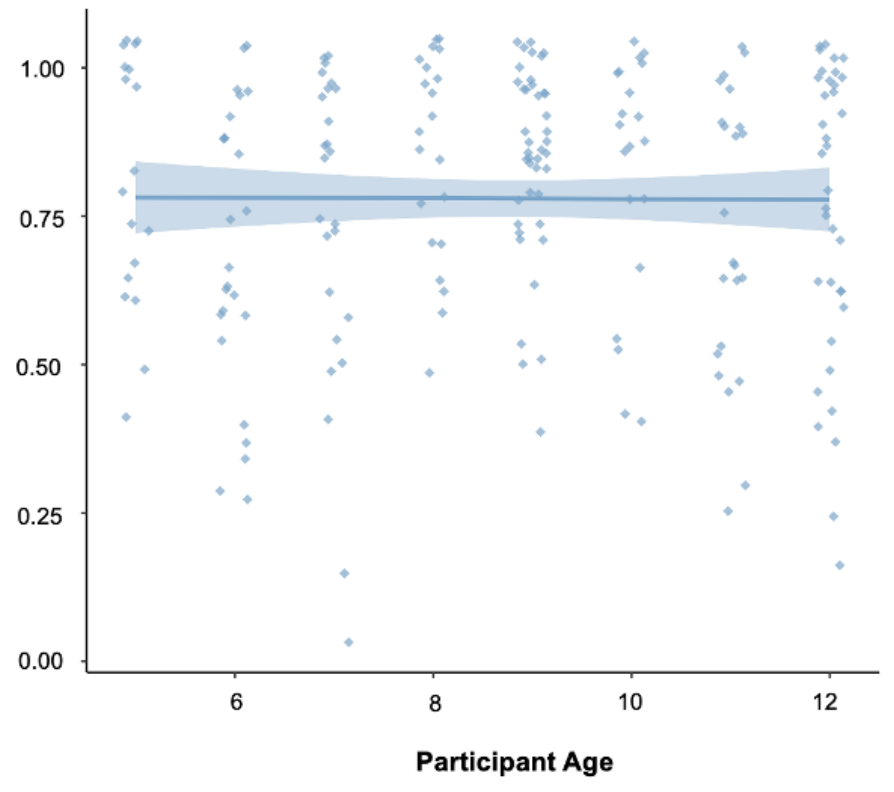

(D)

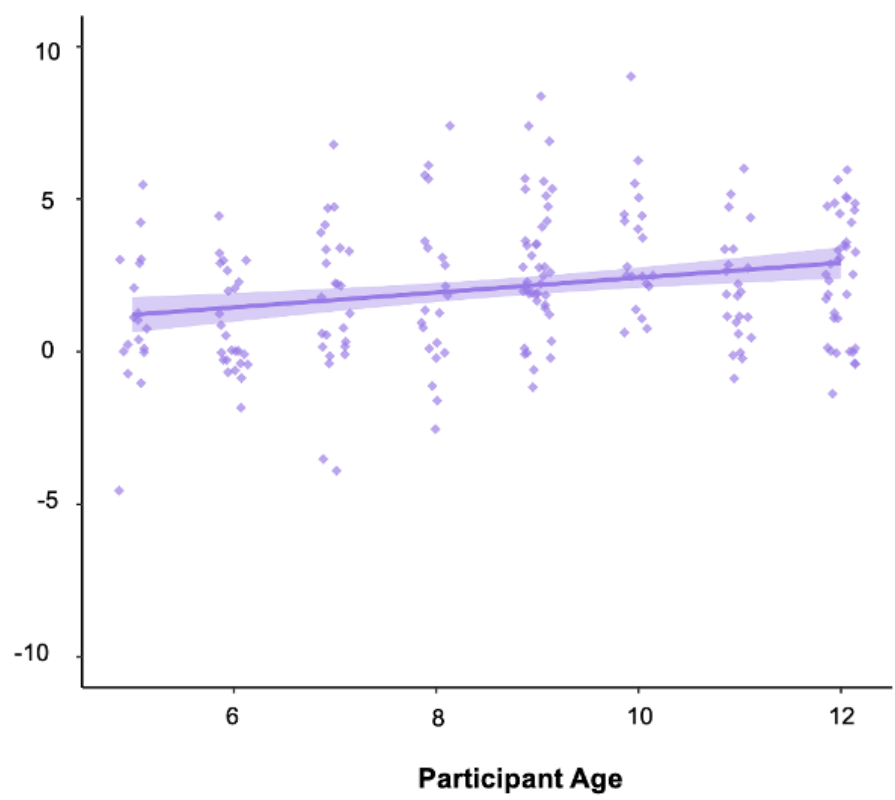

Figure 2 | Children's racial bias (Panel A), and this bias as a function of age (Panel B). Children's race-based status judgments (Panel C), and these judgments as a function age (Panel D). For Panels $\mathrm{A}$ and $\mathrm{C}$, the solid line represents the median, the box represents the interquartile range, and the dots represent outlier values. For Panels B and C, the line represents a linear regression, the dots represent participant responses (jittered), and the error bands represent $+/-1 \mathrm{SE}$.

Second, we examined race-based status judgments. To do so, we subtracted Black status placement, $M=5.97, S D=1.74$, from White status placement, $M=8.02, S D=1.74$, on the ladder 
task for each participant (collapsed across the eight trials), $M=2.06, S D=2.16$ (White targets: $\omega_{t}$ $=.84$; Black targets: $\omega_{t}=.76$ ). A one sample t-test revealed that the Ugandan children placed White targets $\sim 2.06$ steps higher than Black targets on the 10-step status ladder, $t(213)=13.94, p<.001$, $d=0.95$ (Figure 2C). GLMs indicated that the observed status difference strengthened with age, $F(1,210)=11.28, p=.001, \eta_{\mathrm{p}}^{2}=.051$ (Figure 2D), but did not differ by participant gender, $p=$ .243. Notably, a one sample t-test including only the youngest participants, 5-year-olds, still observed a status effect; 5-year-olds rated White targets as higher status than Black targets, $M=$ $1.12, S D=1.86, t(19)=2.70, p=.014, d=0.60$.

Again, we examined whether the observed findings depend on stimuli set and gender. We conducted a repeated-measures GLM with Stimuli Set (CAFE and Google Images) and Target Gender (male and female) as within-participant factors; participants' status judgments functioned as the outcome variable. In line with the racial bias findings, this analysis revealed that participants judged White Google Image targets as higher status than Black Google Image targets, $M=2.46$, $S D=2.70, t=13.32, p<.001$, to a greater extent than they judged White CAFE targets as higher status than Black CAFE targets, $M=1.65, S D=2.31, t=10.47, p<.001, F(1,213)=21.43, p<$ $.001, \eta_{\mathrm{p}}^{2}=.091$. Regarding target gender, participants judged White targets as higher status than Black targets to a greater extent for male targets, $M=2.55, S D=2.70, t=13.81, p<.001$, than for female targets, $M=1.56, S D=2.20, t=10.39, p<.001, F(1,213)=36.95, p<.001, \eta_{\mathrm{p}}{ }^{2}=.148 .{ }^{2}$ Third, we tested whether participants' racial status judgments predicted their racial bias. To do so, we conducted a GLM modeled onto a Poisson distribution with status judgments as the predictor, racial bias as the outcome variable, and participants' age and gender as control variables.

\footnotetext{
${ }^{2}$ Participants also judged female targets, $M=7.22, S D=1.54$, as overall higher status than male targets collapsed across the race trials, $M=6.77, S D=1.49, t(213)=5.11, p<.001$ (i.e., there was a main effect of gender). These results are consistent with the gender trials found in the Supplements.
} 
368 This model revealed that the higher participants placed White over Black targets on the status

369 ladder, the greater their pro-White racial bias, $\beta=.19^{3}, \chi^{2}=12.99, p<.001$ (Figure 3).

370 Demonstrating robustness, this link remained when including Stimuli Set and Gender as additional

371 control variables; a GEE modeled onto a Poisson distribution with Stimuli Set (CAFE, Google

372 Images) and Target Gender (male, female) as within-participant factors, participants' age and

373 gender as continuous and categorical predictors, respectively, and racial bias as the outcome

374 variable revealed consistent findings of status judgments on racial bias, $\chi^{2}=4.99, p=.025$. Finally,

375 none of the four control variables-Stimuli Set, Target Gender, participant age, and participant 376 gender - moderated the positive link between race-based status judgments and racial bias, $p$ s $>$ 377.135.



378

379

380

381

Figure 3 | Children's race-based status judgments (x-axis) predicting their racial bias (y-axis). Univariate linear regression depicted. The line represents a linear regression, the dots represent participant responses (jittered), and the error bands represent +/- $1 \mathrm{SE}$.

\footnotetext{
${ }^{3}$ Standardized coefficient calculated using a linear regression model to provide an easily understandable estimate of effect-size.
} 


\section{Discussion}

The present study provides evidence for the early emergence of racial prejudice, race-based status beliefs, and a connection between the two in a rural community in Uganda, Africa. Specifically, the present work reveals three primary findings: (1) Ugandan children exhibited a robust pro-White bias and this bias remained consistent between the ages of five and twelve; (2) Ugandan children rated White children as higher status than Black children and this effect grew more pronounced with age; and, (3) Ugandan children's judgments of White children as higher status than Black children positively predicted their pro-White preferences.

\section{The Connection Between Racial Prejudice and Status Judgments}

Our findings contribute to the broader scientific understanding of the early emergence of racial prejudice. Specifically, the present results replicate previous research finding pro-White bias (or diminished pro-Black preference) in Black children living in a variety of contexts, including the United States and South Africa (e.g., Aboud \& Skerry, 1984; Dunham et al., 2014; Shutts et al., 2011; Olson et al., 2012). Notably, however, the current results extend the early emergence of racial prejudice to a context where Black children: (1) have had little exposure to White individuals via interpersonal interactions or media content, and (2) are less subject to overt racial discrimination and bias (as compared to most previous samples, for instance, in the United States and South Africa; though see Qian et al., 2021). Given these conditions, our results suggest that pro-White racial bias can emerge even in minimalistic contexts, for instance, in contexts in which clear racial cues and discrimination are not overtly apparent.

We did not find any age effects in terms of racial bias, indicating that children's preference for White targets (relative to Black ones) at five years of age does not differ from their preference at twelve years of age. Placing these age effects in context of other work, the present results 
407 coincide with previous research in South Africa, which also did not find a relationship between 408 age and pro-White racial bias (Shutts et al., 2011; Olson et al., 2012). Other research, however, 409 has documented age effects, although age-related patterns across these findings differ. In 410 particular, research by Dunham and colleagues (2014) found that Black children in South Africa 411 exhibit decreased pro-White bias with age (also see Raabe \& Beelmann, 2011 for related meta412 analytic findings). In contrast, research by Qian and colleagues (2021) found that young Black 413 children (3- to 6-year-olds) in Cameroon exhibit pro-Black racial bias, but older children (above 6 414 years old) and adults do not do so (see Qian et al., 2019 for a similar pattern amongst Chinese 415 children). Considering that the relationship between age and prejudice is clearly complex and 416 varies depending on social context, these results ultimately deserve greater experimental attention 417 in future work.

418 Why did the Ugandan children in our sample exhibit pro-White racial bias? The present 419 findings provide support for the hypothesis that social status may underlie the development of 420 racial prejudice (e.g., Bigler \& Liben, 2007; Shutts, 2015). Specifically, we found that young 421 Ugandan children placed White individuals higher on a status ladder than Black individuals; this 422 finding coheres with previous work indicating that young children believe people of different racial 423 groups differ in social status in line with societal stereotypes (e.g., Olson et al., 2012; Qian et al., 424 2021). Furthermore, the present work - unlike past work conducted in Africa (Dunham et al., 425 2014; Olson et al., 2012; Qian et al., 2021)—documents a direct relationship between children's 426 status beliefs and pro-White bias. That is, children's judgments of White individuals as higher 427 status (than Black individuals) positively predicted their racial bias for White individuals (over 428 Black individuals).

\section{Colorism and Intersectionality}


Regarding secondary findings, we found the observed racial bias and race-based status

431 effects to differ as a function of stimuli set (Google Image vs. CAFE faces). Specifically, Ugandan

432 children preferred White Google Image targets over Black Google Image targets $(\sim 80 \%)$ to a

433 greater extent than they preferred White CAFE targets over Black CAFE targets ( 76\%). And, in

434 line with status judgments and racial bias being linked, participants also judged White Google

435 Image targets as higher in status than Black Google Image targets (2.46 steps higher on the status

436 ladder) compared to their judgments of White CAFE targets over Black CAFE targets (1.65 steps

437 higher on the ladder). Though the two stimuli sets (Google Image vs CAFE) varied on several

438 dimensions (including facial expression, setting, clothing), we suspect these effects emerged due

to effects of colorism — prejudice and discrimination against individuals with darker skin tone (e.g.,

Hunter, 2007; Monk, 2015; Russell, Wilson, \& Hall, 1993; see Norwood \& Foreman, 2013). That

is, the Google Image faces generally featured Black children with a darker skin tone than the CAFE

442 faces, which featured Black children with lighter skin tone. ${ }^{4}$ Notably, this interpretation aligns with

443 past findings that children in the U.S. evaluate faces with darker skin tones more negatively than

444 faces with lighter skin tones (Stepanova et al., 2021). As such, our findings may extend past work

by indicating that the pervasive global nature of colorism (Woodson, 2020) extends even to young children in a remote and homogenously Black context in Africa.

Our findings may also speak to the intersectionality of racial bias (Cole, 2009). The Ugandan children in our sample exhibited greater racial bias towards male than female targets-

449 they preferred the images of White boys over Black boys $(\sim 82 \%)$ to a greater extent than the 450 images of White girls over Black girls ( 73\%). Additionally, and again in line with the observed 451 link between status and racial bias, participants also judged White boys as higher in status than

\footnotetext{
${ }^{4}$ An independent American adult sample conducted on Mechanical Turk $(N=48)$ supported these skin-tone differences, $p<.001$, Cohen's $d=8.77$ (see SOM for more information).
} 
452 Black boys (2.55 steps higher on the status ladder) as compared to White girls versus Black girls

453 (1.56 steps higher on the ladder). These findings replicate past work documenting greater racial 454 prejudice against Black males than females in pre-school children in the United States (Perszyk et 455 al., 2019), and further, support theoretical claims that Black males are particularly likely to 456 experience prejudice, perhaps because Black males are viewed as the prototype of the racially 457 marginalized and subordinated group (e.g., Sidanius and Pratto 1999; Purdie-Vaughns \& Eibach, 458 2008). Finally, the present findings extend past work on the intersectionality of prejudice by 459 showing that Black males are particularly at risk for racial prejudice even in a context that strongly 460 diverges from past work - a remote homogenous Ugandan village.

\section{Origins of Race-Based Status Judgments}

Our findings raise several key questions. First and foremost, why did Ugandan children in our sample judge White individuals as higher status in the first place? As mentioned previously, Uganda was colonized by the British, re-established independence in 1962, and remains part of the British Commonwealth. Although participants in our sample did not directly experience colonization, these events have likely left a powerful mark on Ugandan society. Indeed, scholars have discussed how European colonization leads societies to experience a state of "internalized oppression”, where subordinate group members are consistently socialized to believe the dominant messages put forth by oppressive groups even long after colonization has ended (e.g., Fanon, 1967; Memmi, 1965; Williams, 2012). The present findings, then, are consistent with the notion that children - even those not interacting with White individuals and having limited access to media and the internet - still consciously or unconsciously adopt stereotypical beliefs about race and status that persist due to structural and historical oppression.

At a proximate level, certain experiences or cues may serve to instantiate and maintain the observed race-based status beliefs. First, children in our sample - although not living in a 
476

community with White individuals - do occasionally interact with White people (often via humanitarian aid). It is possible that these experiences are especially impactful on children's early understanding of social groups (especially children low in SES), as White individuals have been portrayed as "saviors" in Africa (e.g., Cole, 2012). Second, children may encounter messaging in their everyday life that reinforces the notion of Whiteness (and lighter skin tone) as good. For instance, in line with colorist notions, the valuing of lighter skin tone over darker skin tone is propagated through music and advertisements in magazines (e.g., Hunter, 2011; Maddox \& Gray, 2002; Okazawa-Rey, Robinson, \& Ward, 1987). Furthermore, children commonly learn (erroneously) that Jesus was a White man (No White Saviors, 2019). And, finally, most children are required to learn English — a language typically associated with Whiteness (Von Esch, Motha, \& Kubota, 2020) — and told that learning English is integral to achieving success.

These examples illuminate just a few ways in which children may acquire status stereotypes about racial groups even in the absence of direct and regular exposure to White people or overt racial discrimination. Because we did not measure any of these beliefs explicitly, however, the current data cannot speak to the degree to which these factors play a role in the observed proWhite race-based status judgments and racial bias. Nonetheless, these examples provide a glimpse into the types of information and messages that children may receive while growing up in Uganda. As a result, we encourage future research to consider these different possibilities and to measure how individual experiences and messaging within a culture - for example, considering Jesus as a White man (Roberts et al., 2020) — may shape the emergence of prejudicial attitudes in children and across societal contexts.

\section{Origins of The Link Between Status and Racial Bias}

Beyond how children acquire stereotypes about Black and White individuals, our findings also raise the question of why - unlike past studies - we found a link between children's race- 
500 based status judgments and their racial bias. Several explanations are possible. For one, children 501 in our sample had less exposure to racial cues other than status (e.g., familiarity, overt and regular 502 experiences of anti-Black racism), at least as compared to the United States and South Africa, 503 where nonverbal cues (stemming from regular cross-race interaction), overt racism, and systemic 504 inequality are all prevalent. As such, status cues in rural Uganda may be particularly salient and 505 meaningful. While this explanation is certainly plausible, children in another location in Africa, 506 Cameroon, did not exhibit a link between status and preference (Qian et al., 2021), even though 507 these children (like the children in Uganda) are less exposed to overt racial cues and systemic 508 racism.

Beyond this, the low SES of our participants may help explain why status beliefs predicted racial bias in our sample. Status differences may be particularly salient for low SES children

511 (Odgers \& Adler, 2017); indeed, past work indicates that lower SES children tend to exhibit greater 512 pro-wealth biases (Dunham et al., 2014; Shutts et al., 2016). Additionally, as noted above, because 513 children in our sample live in a low SES community in Africa, they have experience, albeit limited, 514 with humanitarian aid workers, who are often White. Because of the experience of White aid 515 workers providing goods and services, children in our sample may be especially inclined to judge 516 White individuals as higher in status and to prefer those individuals.

517 At the same time, however, differences between previous studies and our sample may be 518 due to statistical power and sample size rather than due to the contextual features of our sample. 519 That is, Olson et al's (2012) work found a positive yet non-significant relationship between status 520 and racial bias in South Africa, $r=.24(N=84)$. However, this study may have been underpowered 521 to detect a significant relationship between status and racial bias; indeed, Olson et al.'s (2012) 522 study only had $95 \%$ power $($ alpha $=.05)$ to detect a correlation of .37 or greater. Similarly, Dunham 523 et al. (2014) also found a positive yet non-significant relationship between status and racial bias in 
524 South Africa $(r=.19 ; N=103)$; this work had $95 \%$ power to detect a correlation of $r=.34$ or 525 greater. Additionally, Qian and colleagues (2021) found a comparatively smaller non-significant 526 link between status and race judgments in Cameroon $(\beta=.13 ; N=187)$; they had $95 \%$ power to 527 detect a correlation of $r=.26$ or greater. Unlike these studies, however, Qian and colleagues (2019) 528 found a significant correlation between status and explicit racial bias in Chinese participants, $r=$ $529.27(N=200)$; they had $95 \%$ power to detect a correlation of $r=.25$ or greater.

Putting this work in the context of our work, where we find a correlation of .19, it seems

531 plausible that the relationship between status and racial bias may actually exist across contexts and 532 countries but was not observed in past work due to low power (i.e., Type II error). In other words, 533 the reason that we (and Qian et al., 2019) observed significant links between status and racial bias 534 in our studies was due to the comparatively larger size of our samples $(N=214$ and $N=200$ vs. $N$ $535 \sim 125)$ rather than because of the specific features of our sample (e.g., low SES).

536 Taking together our findings and the positive, though non-significant, associations between 537 status and prejudice observed in past work (e.g., Olson et al., 2012; Dunham et al. 2014; Qian et 538 al., 2021), it appears that status and racial prejudice are likely linked, as theorized by Bigler \& Liben (2007). However, this link appears to be much smaller than expected. We consider several potential explanations for the weakness of this link.

First, other factors may play a larger role in the development of racial prejudice than status 542 at the proximate level; for instance, children's racial bias may stem from explicit experiences, such 543 as observing racial bias in the environment (e.g., non-verbal prejudicial cues) or the internalization 544 of stereotypes held by parents and adults (and by society more generally). This would suggest that, 545 while beliefs about status may be a source of racial bias (Wilkerson, 2020), it may fail to manifest 546 strongly as bias early in development. That is, instead of children's cognitive awareness of racial 547 status differences inciting pro-White bias, children's direct experiences with racial discrimination 
and prejudicial cues (e.g., gaze aversion, a cultural idealization of Whiteness) — which result from ultimate race-based status differences - may play a key role in shaping racial bias, and may even serve to reify burgeoning beliefs about the relative status of different racial groups.

Second, the method via which studies, including ours, have measured status may be less than ideal. Potentially, instead of linking status beliefs to racial bias, studies should examine whether status preferences (i.e., a preference for high-status individuals) predicts racial bias at a young age (e.g., Dunham et al., 2014). Ideally, then, future studies should consider both children's race-based status beliefs as well as their status preferences when attempting to predict racial bias. Indeed, if status truly underlies the early emergence of racial prejudice, then young children who recognize race-based status differences as well as prefer high status individuals should be most likely to exhibit racial prejudice.

\section{Limitations}

We consider a few qualifications and limitations of the present work. First, we cannot infer causality from our correlational data. For this reason, we are not able to determine whether Ugandan children's status judgments caused them to prefer White relative to Black individuals, or whether the opposite is occurring (or no causal link at all). Future research could begin to examine this by directly manipulating status or by tracking the developmental trajectory of children's status beliefs and racial bias longitudinally.

Second, unlike our status measure in which children rated White and Black targets separately, our racial bias measure was forced choice. For this reason, the degree to which children exhibited biased racial preferences may be exaggerated (e.g., Dunham \& Degner, 2013). While this technique is frequently relied upon in prejudice research to avoid ceiling effects (e.g., Qian et al., 2021), it is important to acknowledge that children did not have the ability to make an alternative or neutral choice or choose both children. Nonetheless, we note that children did have 
572 the option of selecting White and Black children evenly across the eight trials, and they did not do

573 so. Relatedly, even though the status measure involved independently rating the individual targets

574 (as was the case in previous research; Mandalaywala et al., 2020), the experimenter presented

575 participants with images of a White target and a Black target simultaneously as a way to direct

576 participants attention towards race when making status judgments. It is possible, then, that had we

577 presented the faces individually the effects documented here would be attenuated.

Third, our racial bias measure involved asking children to select someone to play with

579 (rather than selecting someone to avoid; i.e., approach versus avoidance), making it challenging to interpret children's choices as measuring negative attitudes towards their ingroup. On one hand, children's responses may reflect a preference for White individuals; on the other, such responses may reflect a dislike of Black individuals. Said another way, participants' racial bias may be driven by a general positivity bias towards White individuals or by holding negative stereotypes of Black

584 individuals (or both). In turn, it is unclear whether children's biased responses represent racial prejudice in a strict sense. We opted to measure prejudice in this way ("play with" rather than “avoid") because past studies on racial bias with children have tended to ask positively framed question ("Who do you like more") than negatively framed ones ("Who do you like less") (e.g., Shutts et al., 2011). Our findings should be interpreted with this qualification in mind.

Fourth, and finally, one could argue that children in our study exhibited pro-White biases

591 explanation for our results, we did find race-based status judgments to predict pro-White bias, 592 demonstrating that at least a portion of variation in the observed racial bias was predicted by status 593 rather than by a novelty preference. Additionally, past research indicates that there is little reason to think that young children prefer societal outliers or minorities or consider such individuals 
596 White individuals are likely as similarly novel as in Uganda, did not prefer to interact with White 597 individuals (Qian et al., 2021). Nonetheless, future research should further explore the potential 598 role of novelty.

\section{Concluding Remarks}

600 Ultimately, if we want to understand the origins and maintenance of prejudice, we must 601 focus on understanding its emergence (Bigler \& Liben, 2007). Here, we contribute to this literature 602 by demonstrating that racial prejudice can develop at an early age even in a homogenous and 603 remote community with less regular and overt exposure to racial discrimination than previously 604 tested locations. Furthermore, we demonstrate that this observed pro-White racial prejudice is 605 predicted by race-based status beliefs as theorized in previous work (Bilger \& Liben, 2007). In 606 turn, our findings are consistent with the possibility that status cues are potent enough to incite 607 racial bias in the absence of other racial cues (such as explicit discrimination), and that racial 608 hierarchies and racial prejudice can spread to young children even in racially homogenous 609 contexts. Yet, we also note that the observed link between status and racial bias was quite weak, 610 and thus, factors other than status may take precedence in motivating the early emergence of racial 611 prejudice. Taken together, then, the present findings contribute to our understanding of the factors 612 motivating the early emergence of prejudice in young childhood. 
614 
616 The authors would like to thank the Mind and Development Lab for helpful feedback on the present

617 studies. We would like to thank the children, parents, schools, and teachers who participated in

618 this research. We would also like to thank the people who helped in the data collection efforts for

619 this project, including Kaleeba, Nicholas Sselu, Christine Kaleeba, Thadeus Kasumba, Julius

620 Mpagi, Caroline Atuk, and Doreen Twenatween. The work was funded by the Klaus J. Jacobs

621 Research Prize awarded by the Jacobs Foundation. Additionally, it is helpful to understand our

622 positionality and, therefore, our lens on the data. The first shared first-author self-identifies as

623 white American; the second shared first-author self-identifies as a white German-American; the

624 third author self-identifies as white American; and the final author self-identifies as a multiracial

625 American. The third author grew up in Kampala, Uganda from 5 months to 7 years of age and has

626 connections to the testing location. Having conducted several humanitarian aid projects there in

627 the past ten years, the third author has an established relationship with the school, knows the school

628 administration well, and has fundraised money to donate to the school. All study authors

629 contributed to interpreting the findings and the implications of the study. 


\section{References}

Aboud, F. E. (1988). Children and prejudice. B. Blackwell.

Aboud, F. E., \& Steele, J. R. (2017). Theoretical perspectives on the development of implicit and explicit prejudice. The Wiley Handbook of Group Processes in Children and Adolescents, $165-183$.

Aboud, F. E., \& Skerry, S. A. (1984). The development of ethnic attitudes: A critical review. Journal of Cross-Cultural Psychology, 15, 3-34.

Amir, D., Valeggia, C., Srinivasan, M., Sugiyama, L. S., \& Dunham, Y. (2019). Measuring subjective social status in children of diverse societies. PloS one, 14, e0226550.

Baker, W. (2001). Uganda: The marginalization of minorities. Retrieved from http://citeseerx.ist.psu.edu/viewdoc/download?doi=10.1.1.638.844\&rep=rep1\&type=pdf

Bigler, R. S., \& Liben, L. S. (2006). A developmental intergroup theory of social stereotypes and prejudice. Advances in Child Development and Behavior, 34, 39-89.

Bigler, R. S., \& Liben, L. S. (2007). Developmental intergroup theory: Explaining and reducing children's social stereotyping and prejudice. Current Directions in Psychological Science, 16, 162-166.

Brondolo, E., Lackey, S., \& Love, E. (2012). Race and health: Racial disparities in hypertension and links between racism and health. In A. Baum, T. A. Revenson, \& J. Singer (Eds.), Handbook of health psychology (p. 569-594). Psychology Press.

Cole, T. (2012, March 21). The white-savior industrial complex. The Atlantic. Retrieved from https://www.theatlantic.com/international/archive/2012/03/the-white-savior-industrialcomplex/254843/

Cole, E. R. (2009). Intersectionality and research in psychology. American Psychologist, 64, 170180. 
655 656

Duckitt, J., Wall, C., \& Pokroy, B. (1999). Color bias and racial preference in White South African preschool children. The Journal of Genetic Psychology, 160, 143-154.

Dunham, Y., Newheiser, A. K., Hoosain, L., Merrill, A., \& Olson, K. R. (2014). From a different vantage: Intergroup attitudes among children from low-and intermediate-status racial groups. Social Cognition, 32, 1-21.

Dunham, Y., \& Degner, J. (2013). From categories to exemplars (and back again). In M. Banaji \& S. Gelman (Eds.) Navigating the social world: What infants, children, and other species can teach us, pp. 275-280. Oxford University Press: New York, NY.

Dunham, Y., Baron, A. S., \& Banaji, M. R. (2006). From American city to Japanese village: A cross-cultural investigation of implicit race attitudes. Child Development, 77, 1268-1281.

Edwards, C. P., \& Lewis, M. (1979). Young children's concepts of social relations: Social functions and social objects. In The child and its family (pp. 245-266). Springer, Boston, MA.

Elenbaas, L., \& Killen, M. (2016). Age-related changes in children's associations of economic resources and race. Frontiers in Psychology, 7, 884.

Fanon, F. (2008). Black skin, white masks. Grove Press.

Feagin, J. (2013). Systemic racism: A theory of oppression. Routledge.

Fincham, F. D. (1978). Race concepts among Black and White preschool children in South Africa. Journal of Behavioural Science, 2, 291-295.

French, D. C. (1987). Children's social interaction with older, younger, and same-age peers. Journal of Social and Personal Relationships, 4, 63-86.

Gregor, A. J., \& McPherson, D. A. (1966). Racial preference and ego-identity among white and Bantu children in the republic of South Africa. Genetic Psychology Monographs, 73, 217253. 
Gollwitzer, A., Marshall, J., \& Bargh, J. A. (2019). Pattern deviancy aversion predicts prejudice via a dislike of statistical minorities. Journal of Experimental Psychology: General, 149, $828-854$.

Hamilton, D. L. (1981). Stereotyping and intergroup behavior: Some thoughts on the cognitive approach. Cognitive Processes in Stereotyping and Intergroup Behavior, 333-353.

Horwitz, S. R., Shutts, K., \& Olson, K. R. (2014). Social class differences produce social group preferences. Developmental Science, 17, 991-1002.

Hraba, J., \& Grant, G. (1970). Black is beautiful: A reexamination of racial preference and identification. Journal of Personality and Social Psychology, 16, 398-402.

Hunter, M. L. (2011). Buying racial capital: Skin-bleaching and cosmetic surgery in a globalized world. The Journal of Pan African Studies, 4, 142-164.

Lee, Y., Muennig, P., Kawachi, I., \& Hatzenbuehler, M. L. (2015). Effects of racial prejudice on the health of communities: A multilevel survival analysis. American Journal of Public Health, 105, 2349-2355.

LoBue, V., \& Thrasher, C. (2014). The child affective facial expression (CAFÉ) set. Databrary, $10, \mathrm{~B} 7301 \mathrm{~K}$.

LoBue, V., \& Thrasher, C. (2015). The Child Affective Facial Expression (CAFE) set: Validity and reliability from untrained adults. Frontiers in Psychology, 5, 1532.

Maddox, K. B., \& Gray, S. A. (2002). Cognitive representations of Black Americans: Reexploring the role of skin tone. Personality and Social Psychology Bulletin, 28, 250-259.

Mandalaywala, T. M., Tai, C., \& Rhodes, M. (2020). Children's use of race and gender as cues to social status. PloS one, 15, e0234398.

Memmi, A. (2013). The colonizer and the colonized. Routledge.

Monk Jr, E. P. (2015). The cost of color: Skin color, discrimination, and health among African- 
Americans. American Journal of Sociology, 121, 396-444.

704 National Census Data: Mukono. (2014).

705

706

707

708

709

710

711

712

713

714

715

716

717

718

719

720

721

722

723

724

725
Retrieved from https://www.ubos.org/wpcontent/uploads/publications/2014CensusProfiles/MUKONO.pdf.

Newheiser, A. K., \& Olson, K. R. (2012). White and Black American children's implicit intergroup bias. Journal of Experimental Social Psychology, 48, 264-270.

Newheiser, A. K., Dunham, Y., Merrill, A., Hoosain, L., \& Olson, K. R. (2014). Preference for high status predicts implicit outgroup bias among children from low-status groups. Developmental Psychology, 50, 1081-1090.

Norwood, K. J., \& Foreman, V. S. (2013). The ubiquitousness of colorism: Then and now. In Color Matters (pp. 17-36). Routledge.

No White Saviors (2019). Jesus was not white. Retrieved from: https://nowhitesaviors.org/jesuswas-not-white/

Odgers, C. L., \& Adler, N. E. (2018). Challenges for low-income children in an era of increasing income inequality. Child Development Perspectives, 12, 128-133.

Okazawa-Rey, M., Robinson, T., \& Ward, J. V. (1987). Black women and the politics of skin color and hair. Women \& Therapy, 6, 89-102.

Olson, K. R., Shutts, K., Kinzler, K. D., \& Weisman, K. G. (2012). Children associate racial groups with wealth: Evidence from South Africa. Child Development, 83, 1884-1899.

Perszyk, D. R., Lei, R. F., Bodenhausen, G. V., Richeson, J. A., \& Waxman, S. R. (2019). Bias at the intersection of race and gender: Evidence from preschool-aged children. Developmental Science, 22, e12788.

Pew Research Center (2016). On views of race and inequality, Blacks and Whites are worlds apart. 
Retrieved from https://www.pewresearch.org/social-trends/2016/06/27/1-demographictrends-and-economic-well-being/

Press, L., Burt, I., \& Barling, J. (1979). Racial preferences among South African White and Black preschool children. Journal of Social Psychology, 107, 125-126.

Purdie-Vaughns, V., \& Eibach, R. P. (2008). Intersectional invisibility: The distinctive advantages and disadvantages of multiple subordinate-group identities. Sex Roles, 59, 377-391.

Qian, M., Heyman, G. D., Quinn, P. C., Messi, F. A., Fu, G., \& Lee, K. (2021). Age-related differences in implicit and explicit racial biases in Cameroonians. Developmental Psychology, 57, 386-396.

Qian, M. K., Heyman, G. D., Quinn, P. C., Fu, G., \& Lee, K. (2019). Differential developmental courses of implicit and explicit biases for different other-race classes. Developmental Psychology, 55, 1440-1452.

Raabe, T., \& Beelmann, A. (2011). Development of ethnic, racial, and national prejudice in childhood and adolescence: A multinational meta-analysis of age differences. Child Development, 82, 1715-1737.

Raissi, A., \& Steele, J. R. (2021). Does emotional expression moderate implicit racial bias? Examining bias following smiling and angry primes. Social Cognition, 39, 570-590.

Roberts, S. O., Weisman, K., Lane, J. D., Williams, A., Camp, N. P., Wang, M., ... \& Griffiths, C. (2020). God as a White man: A psychological barrier to conceptualizing Black people and women as leadership worthy. Journal of Personality and Social Psychology, 119, 12901315.

Russell, K., Wilson, M., \& Hall, R. E. (1993). The color complex: The politics of skin color among African Americans. Anchor.

Shutts, K. (2015). Young children's preferences: Gender, race, and social status. Child 
Development Perspectives, 9, 262-266.

751 Sidanius, J., \& Pratto, F. (1999). Social dominance: An intergroup theory of social hierarchy and oppression. New York: Cambridge University Press.

753

754

755

756

757

758

759

760

761

762

763

764

765

766

767

768

769

770

771

772

773

Sigelman, C. K. (2012). Rich man, poor man: Developmental differences in attributions and perceptions. Journal of Experimental Child Psychology, 113, 415-429.

Shutts, K., Brey, E. L., Dornbusch, L. A., Slywotzky, N., \& Olson, K. R. (2016). Children use wealth cues to evaluate others. PloS one, 11, e0149360.

Shutts, K., Kinzler, K. D., Katz, R. C., Tredoux, C., \& Spelke, E. S. (2011). Race preferences in children: Insights from South Africa. Developmental Science, 14, 1283-1291.

Steele, J. R., George, M., Williams, A., \& Tay, E. (2018). A cross-cultural investigation of children's implicit attitudes toward White and Black racial outgroups. Developmental Science, 21, e12673.

Stepanova, E. V., Dunham, Y., Rex, M., \& Hagiwara, N. (2021). What drives racial attitudes in elementary school children: Skin tone, facial physiognomy, or both?. Psychological Reports, 124, 809-838.

Von Esch, K. S., Motha, S., \& Kubota, R. (2020). Race and language teaching. Language Teaching, 53, 391-421.

Weisbuch, M., Pauker, K., \& Ambady, N. (2009). The subtle transmission of race bias via televised nonverbal behavior. Science, 326, 1711-1714.

Wilkerson, I. (2020). Caste: The Origins of Our Discontents. Random House.

Williams, T. K. (2012). Understanding internalized oppression: A theoretical conceptualization of internalized subordination. University of Massachusetts Amherst.

Woodson, K. M. (2020). Colorism: Investigating a global phenomenon.

World Bank Database: Uganda. (2021). 
Retrieved from https://data.worldbank.org/country/uganda

775 